\title{
Optimization Design And Simulation Of Microgrid In Amdjarass Town, Chad
}

\author{
Wu Qing ${ }^{1,2, *}$, Fan Zhongyi ${ }^{1,2}$, Zhang Jintao ${ }^{1}$, Sun Qin ${ }^{1}$, Yang Junjie ${ }^{1}$ \\ ${ }^{1}$ Hangzhou Huachen Electric Power Control Co.,LTD, Hangzhou 310000, China \\ ${ }^{2}$ College of Energy and Electricity, Hohai University, Nanjing 210000, China
}

\begin{abstract}
How to supply electricity to the remote areas has become a very pressing issue for some countries which do not have the ability to connect all power grids to the whole country temporarily. At the same time, with the increase of fossil fuel costs and the continuous development of renewable energy generation technology, the construction of a hybrid renewable energy microgrid system seems to become an economic and technical approach to resolve the power shortage problem in the remote areas of some countries. Based on the analysis of local natural resources and load conditions, this paper designed a microgrid system which contains the wind turbines, PV systems, a diesel generator and an energy storage module to meet the power supply needs of the small town Amdjarass in Chad. Then the authors optimized the capacity of this microgrid and estimated the cost of this system with the utilization of HOMER software. In the end, this paper set the optimal configuration scheme with the target of the lowest COE and analyzed the sensitivity of some important parameters which could affect the economic performance.
\end{abstract}

\section{Introduction}

The electricity has become an indispensable source of power for the Human Being. However, a general lack of electricity still refrain the development of local social economy and inhabitants' livelihood in some areas of Asia and Africa. Although most of the power-deficient areas are remote and scattered with few large power grids connected, these areas often have abundant natural resources. Using these renewable resources to generate electricity will help protect the local environment and reduce the cost of the generation compared with the traditional methods. But there comes to a question: relying solely on a single new energy source will result in low reliability of power supply owing to the unavoidable weather changes. The solutions appeared with the continuous breakthrough of the key technologies of the microgrid system ${ }^{[1]}$ and the rise of the energy storage industry. The construction of the hybrid microgrid system, which contains the wind turbines, PV systems, diesel generators and an energy storage module, has become a feasible solution to supply power to remote areas ${ }^{[2]}$.

The microgrid system is mainly composed of distributed energy resources, energy storage systems and converters. The details such as the type of energy and the capacity configuration, need to be determined according to the local own situation. The reasonable configuration of the capacity must make the microgrid meet the electricity balanced demand and improve the Ecoenvironmental benefits when operating. At present, some software for the design and simulation of microgrids have already been developed. The HOMER software developed by the US Department of Energy's Renewable Energy Laboratory is the most widely used. HOMER can simulate and optimize the microgrid system, and it has gradually become the standard for Distributed Energy System (DES) simulation. Joan D Rozario and Shahinur Rehman from Bangladesh used the photovoltaic and biogas modules in the HOMER software for simulation analysis of the microgrid and provided a cost-effective solution ${ }^{[3]}$. In order to electrify a village in India, Kiran Preet Kuar and Gursewak Singh used HOMER software to design a hybrid system of solar and bioenergy to meet local electricity needs ${ }^{[4]}$. Ibrahim Elsayed from Egypt and others found that building a hybrid system of PV (photovoltaic) and wind turbines in remote areas of Egypt was more reliable and economical than independent PV systems ${ }^{[5]}$. Zhang Chaohui from China designed the microgrid system on Bawean Island and obtained the optimal capacity configuration by using HOMER software ${ }^{[6]}$. These series of research results demonstrated the feasibility of establishing an independent hybrid microgrid system in remote areas.

In order to solve the power supply problem in Amdjarass in Chad, this paper proposes a solution to build a hybrid microgrid system to supply power to the town based on the analysis of the local natural resources, then optimizes the capacity of this microgrid with the HOMER software and compares the differences between with or without a diesel generator. In the end, some sensitive parameters of the results are analyzed for

\footnotetext{
* Corresponding author: wuqinghhu@163.com
} 
sensitivity analyzation, and the results propose some variables that need to be focused on.

\section{Local Resources and Electrical Load}

Chad is located in the middle of Africa. The project is located in the town of Amdjarass, the eastern part of the country. The latitude and longitude coordinates are: $22^{\circ} 49^{\prime} 58.14^{\prime \prime}$ E, $16^{\circ} 05^{\prime} 09.09^{\prime \prime} \mathrm{N}$.

\subsection{Solar Resources}

Analyzing the solar radiation data was based on the GIS: The average annual solar radiation on the ground in this region can reach about $8661 \mathrm{MJ} / \mathrm{m} 2$, which signifies that the solar energy resources in the region were quite abundant. Photovoltaic panels are suitable for layout as the result of $979 \mathrm{~m}$ local elevation and the relatively flat terrain.

\subsection{Wind resources}

According to the database of the Global Wind Atlas, the average of the wind power density $(50 \mathrm{~m}$ above the ground) in the area is about $400 \mathrm{~W} / \mathrm{m} 2$. It means that the wind resources are very rich. After the field investigation, our engineers concluded that the planning area was suitable for the construction of wind turbines with the condition of plat terrain and less rocks.

\subsection{Electrical Load}

National power grid does not connect all the territory of Chad. Each small town is an independent diesel power microgrid system. Amdjarass has constructed the Presidential Residences, the Conference Centers, hospitals, UN humanitarian camps, hotels and other facilities. For the reason that Amdjarass is the hometown of the president of Chad, the president will return to the town for recuperation every year and will receive the foreign guests in this town. Therefore, the project was demanded to improve the reliability and the economy of the local power supply by building a hybrid microgrid system. The population of Amdjarass is small, and the mainly type of electrical load is residential electricity. The daily maximum load is about $0.6 \mathrm{MW}$. The load data is shown in Fig.1.

\section{Module Modelling}

Before the simulation, the system needed to select the included modules on HOMER to build the hybrid microgrid system, and input the detailed parameters of the relevant equipments so that HOMER can be successfully modeled.

\subsection{PV Module}

The output of photovoltaic generation was closely related to the solar radiation intensity and temperature at the installation $\operatorname{site}^{[7]}$. The output power could be expressed as:

$$
P_{P V}=Y_{P V} \mathrm{f}_{P V}\left(\frac{\bar{G}_{T}}{\bar{G}_{T, S T C}}\right)\left[1+\alpha_{P}\left(T_{\mathrm{c}}-T_{\mathrm{c}, S T C}\right)\right]
$$

$Y_{P V}$ : The rated capacity of the PV array, meaning its power output under standard conditions [kW]

$\mathrm{f}_{\mathrm{PV}}$ : The PV derating factor [\%]

$\bar{G}_{T}$ : The solar radiation incident on the PV array in the current time step $[\mathrm{kW} / \mathrm{m} 2]$

$\bar{G}_{T, S T C}:$ The incident radiation at standard test conditions $[1 \mathrm{~kW} / \mathrm{m} 2]$

$\alpha_{P}$ : The temperature coefficient of power $\left[\% /{ }^{\circ} \mathrm{C}\right]$

$T_{\mathrm{c}}$ : The PV cell temperature in the current time step $\left[{ }^{\circ} \mathrm{C}\right]$

$T_{\text {c, STC }}:$ The PV cell temperature under standard test conditions $\left[25^{\circ} \mathrm{C}\right]$

\subsection{Wind Turbine Module}

This paper needed to calculate the wind speed at the height of the hub and predicted the output of the wind turbine referring to the power curve of the fan while calculating the output of the wind turbine. In the condition of the logarithmic model, the wind speed at the hub height could be derived from:

$$
V_{\text {hub }}=V_{\text {anem }} \cdot \frac{\ln \left(\mathrm{z}_{\text {hub }} / \mathrm{z}_{0}\right)}{\ln \left(\mathrm{z}_{\text {anem }} / \mathrm{z}_{0}\right)}
$$

$V_{\text {hub }}$ : the wind speed at the hub height of the wind turbine $[\mathrm{m} / \mathrm{s}]$

$V_{\text {anem }}:$ the wind speed at the height of anemometer $[\mathrm{m} / \mathrm{s}]$

$\mathrm{z}_{\text {hub }}$ : the hub height of the wind turbine [m]

$\mathrm{z}_{\text {anem }}:$ the anemometer height $[\mathrm{m}]$

$\mathrm{z}_{0}: \quad$ the surface roughness length [m]

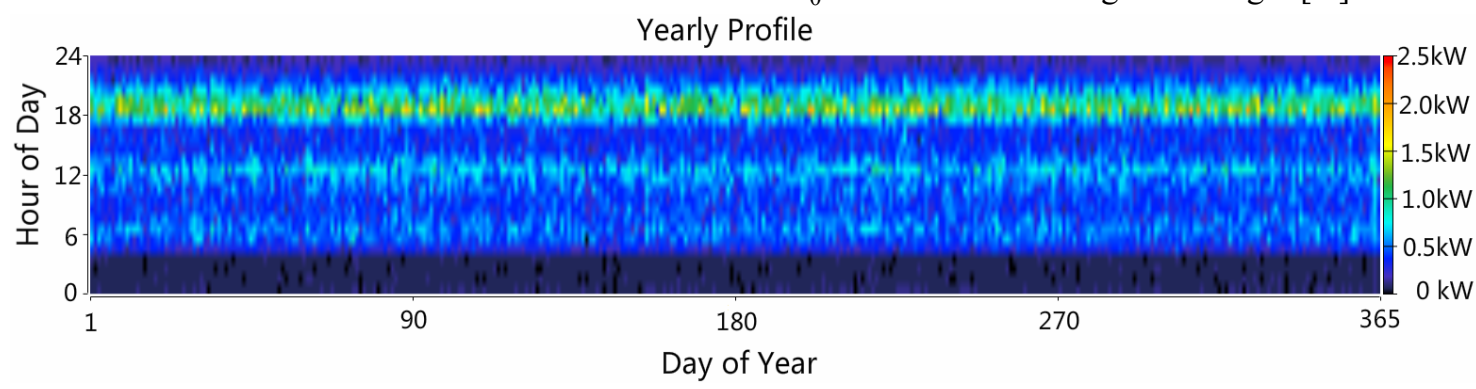

Fig. 1. Map of load data of Amdjarass 
The output of the fan is also affected by the actual air density. In order to be able to adapt to the actual situation, it was necessary to multiply the air density ratio while predicting the output according to the curve.

$$
P_{W T G}=\left(\frac{\rho}{\rho_{0}}\right) \cdot P_{W T G, S T P}
$$

$P_{W T G}: \quad$ the wind turbine power output $[\mathrm{kW}]$

$P_{W T G, S T P}:$ the wind turbine power output at standard temperature and pressure $[\mathrm{kW}]$

$\rho: \quad$ the actual air density $[\mathrm{kg} / \mathrm{m} 3]$

$\rho_{0}$ : $\quad$ the air density at standard temperature

\subsection{Diesel engine module}

In this design, the renewable energy was preferentially used for power supply, and the rest was provided by diesel generators and energy storage batteries. The diesel generator mainly served as a backup to improve the power supply reliability of the hybrid microgrid system.

\subsection{Battery module}

Lithium iron phosphate battery was selected for energy storage battery because of its advantages of high energy density and good safety ${ }^{[8]}$. The life of the battery was ten years and the battery capacity would decay to $90 \%$ over its lifetime. The maximum SOC was set to $100 \%$ and the minimum SOC was set to $20 \%$.

\section{Optimization And Sensitivity Analysis}

\subsection{Capacity Optimization Results}

The hybrid system, established by HOMER, included wind turbines, photovoltaics, diesel generator, batteries, inverters, and AC and DC busses which connected them. The system modeled by HOMER is shown in Fig.2.

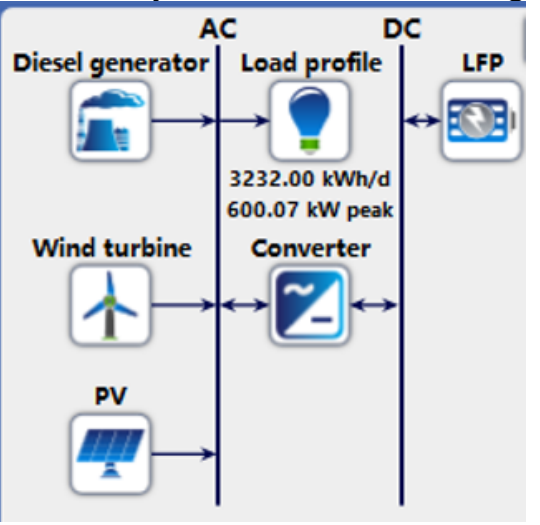

Fig. 2. Scenery firewood hybrid system diagram

After setting the parameters of each components in the hybrid system, our researchers started the simulation, and HOMER automatically generated all possible configuration results. It arranged the results according to the net present cost from low to high. The configuration results are shown in Table.1.

Table.1. Capacity configuration results

\begin{tabular}{|c|c|c|c|c|}
\hline & Sol.1 & Sol.2 & Sol.3 & Sol.4 \\
\hline PV(KW) & 1000 & 1000 & 1000 & 1000 \\
\hline Wind(KW) & 500 & 500 & 1000 & 1500 \\
\hline Diesel(KW) & 200 & - & 300 & 700 \\
\hline Battery(KW) & 2020 & 3030 & 2020 & 3030 \\
\hline NPC(\$) & 7.20 & 7.63 & 8.02 & 9.34 \\
\hline COE(\$) & 0.472 & 0.500 & 0.526 & 0.613 \\
\hline
\end{tabular}

Among these configuration results, the net present costs (NPC) of the first and second solution were relatively close. The latter solution increased the capacity of each module, and the cost also increased accordingly. The main difference between the first solution and the second solution was that the second solution canceled the diesel generator and met the power supply by increasing the battery capacity. From the perspective of net present cost, the first solution was slightly better than the second one. But from the perspective of payback, the return on investment of solution 2 was relatively high, and it could save money during the project cycle, and the time to payback is 13.8 years. The detail can be seen from Fig.3.

\begin{tabular}{|l|l|}
\hline \multicolumn{1}{|c|}{ Metric } & \multicolumn{1}{c|}{ Value } \\
\hline Present worth $(\$)$ & $(\$ 430,955)$ \\
\hline Annual worth $(\$ / y r)$ & $(\$ 33,336)$ \\
\hline Return on investment $(\%)$ & 0.5 \\
\hline Internal rate of return (\%) & 0.8 \\
\hline Simple payback (yr) & 13.39 \\
\hline Discounted payback (yr) & 13.90 \\
\hline
\end{tabular}

Fig. 3. Comparison To Economy Between Option 1 And Option 2

Considering that the location of the project is the hometown of the President of Chad, the president needs to carry out some foreign affairs activities in the local area, and the economic differences between the first and second options are not great. Therefore, in order to improve the reliability of power supply, the Solution with a $200 \mathrm{~kW}$ diesel generator was still selected as the optimal configuration.

\subsection{Sensitivity analysis}

As the cost of equipment and the price of fuel change with market fluctuations, the investment cost of the hybrid system will be affected by these factors. In addition, the volatility and randomness of wind speed and solar radiation will also affect the final power supply. In order to study the impact of these factors on the results, this paper also analyzed the sensitivity of these 
important factors, the relationship between the cost of electricity (COE) and the rate of change of various sensitive factors is shown in the Fig.4.

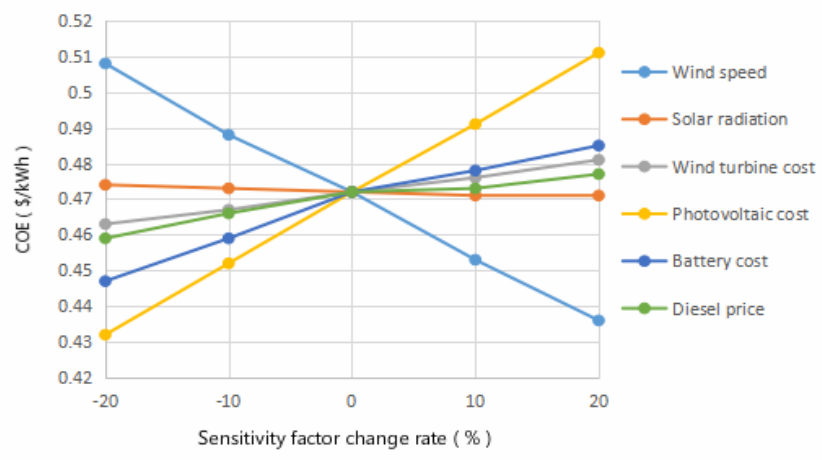

Fig. 4. Relationship between COE and the rate of change of sensitive factors

It can be seen from Fig.4 that the COE decreases with the increase of wind speed and solar radiation, and increases with the raise of the cost of each kind of equipments. COE has a large change on the curve when the factors are the wind speed, PV investment cost and battery investment cost. But when it comes to the other factors, the change on the curve was small. The explanation is that the main factors affecting the cost of power supply are the investment costs of wind speed, photovoltaics and storage batteries. These factors should be focused on while constructing this hybrid microgrid system.

\section{Conclusion}

The construction of a hybrid off-grid microgrid system is an effective solution to solve the problem of power supply in remote areas. This study verified the feasibility of building a hybrid renewable energy microgrid system in the town Amdjaras in Chad to solve the local power supply problem. The research results showed that the initial investment cost would be reduced in the case of equipping a diesel generator, but considering the longterm operation of the project, its economy was not as good as the case of no equipping a diesel generator. Considering the requirements of economy and power supply reliability, this study determined the optimal capacity allocation scheme with a diesel generator(200kW), a photovoltaic system $(1000 \mathrm{~kW})$, a wind turbine $(500 \mathrm{~kW})$ and an energy storage station(2020kWh). NPC under this scheme was 7.2 million dollars, COE was 0.472 dollars. In addition, through analysis of sensitivity, the circumstances were found that the wind speed, photovoltaic and battery cost were the most important factors affecting the investment cost of this microgrid system. In order to improve the economy of the project, the wind speed measurement in the field should be carried out locally to get more accurate wind speed data while minimizing the investment cost of photovoltaics and batteries.

\section{References}

1. Xinfa Yang and Jian Su. Overview on Micro-grid Technology, Proceedings of the CSEE,34(01):57-70. (2014).

2. Wei Fan. Research on Distribution Characteristics of Wind/Solar/Water Resources and Optimized Configuration in Remote Mountainous Areas. Thesis, Hunan University.(2017).

3. J. D'Rozario, S. Shams, S. Rahman, A. Sharif, and E. Basher, "Cost effective solar-biogas hybrid power generation system," in Industrial Technology (ICIT), pp. 2756-2760: IEEE. (2015).

4. K. Kaur and G. S. Brar, "Solar-Biogas-Biomass Hybrid Electrical Power Generation for a Village (a case study)," International Journal of Engineering Development and Research, 4 (2016).

5. Ibrahim Elsayed, Ibrahim Nassar, Optimization And Economic Evaluation Of Small Scale Hybrid Solar/Wind Power For Remote Areas In Egypt. 2017 Nineteenth International Middle East Power Systems Conference (MEPCON), pp.25-30. (2017).

6. Zhang Chaohui. Research on Optimal Sizing Method of Wind-Solar-Diesel-Battery Microgrid System in Bawean Island, thesis, North China Electric Power University. (2018).

7. Wang $\mathrm{Fu}$, Lin Zhou. Research on Engineering Analytical Model of Solar Cells. Transactions Of China Electrotechnical Society, 26(10):211-216. (2017).

8. Fang Zhou, Si Liu, Min Hou. Application and development tendency of lithium battery technology in energy storage field. Chinese Journal Of Power Science, 43(02):348-350. (2019). 